\title{
Qualitative evaluation of the flow supplied by personalized ventilation using schlieren imaging and thermography
}

\author{
Hayder Alsaad, Conrad Voelker \\ Bauhaus-University Weimar, Department of Building Physics \\ Coudraystrasse 11A, Room 110 \\ 99423 Weimar, Germany \\ Email: hayder.alsaad@uni-weimar.de,conrad.voelker@uni-weimar.de
}

(Received 13 June 2019; Received in revised form 27 August 2019; Accepted 1 October 2019)

\section{Copyright Notice}

This is the accepted manuscript of the article published by Elsevier in Building and Environment 167 (2020) 106450, which can be found at https://doi.org/10.1016/j.buildenv.2019.106450.

(C) 2019. The accepted version is made available under the CC-BY-NC-ND 4.0 license https://creativecommons.org/licenses/bync-nd/4.0/.0360-1323/C 2019 Elsevier Ltd. All rights reserved. This article may be downloaded for personal use only. Any other use requires prior permission of the authors and Elsevier Ltd.

\footnotetext{
Abstract

Personalized ventilation (PV) is a mean of delivering conditioned outdoor air into the breathing zone of the occupants. This study aims to qualitatively investigate the personalized flows using two methods of visualization: (1) schlieren imaging using a large schlieren mirror and (2) thermography using an infrared camera. While the schlieren imaging was used to render the velocity and mass transport of the supplied flow, thermography was implemented to visualize the air temperature distribution induced by the PV. Both studies were conducted using a thermal manikin to simulate an occupant facing a PV outlet. As a reference, the flow supplied by an axial fan and a cased axial fan was visualized with the schlieren system as well and compared to the flow supplied by PV. Schlieren visualization results indicate that the steady, low-turbulence flow supplied by PV was able to penetrate the thermal convective boundary layer encasing the manikin's body, providing clean air for inhalation. Contrarily, the axial fan diffused the supplied air over a large target area with high turbulence intensity; it only disturbed the convective boundary layer rather than destroying it. The cased fan supplied a flow with a reduced target area which allowed supplying more air into the breathing zone compared to the fan. The results of thermography visualization showed that the supplied cool air from PV penetrated the coronashaped thermal boundary layer. Furthermore, the supplied air cooled the surface temperature of the face, which indicates the large impact of PV on local thermal sensation and comfort.
} 


\section{Introduction}

Commonly in the practice, the building ventilation system treats the air in whole volume of the room. This can result in user dissatisfaction as the ventilation system does not account for the individual preferences of the thermal environment between the occupants. Moreover, the supplied conditioned outdoor air mixes with contaminated room air before reaching the occupants, which results in lower inhaled air quality. Unlike the widely-used total-volume ventilation systems, personalized ventilation systems (PV) supply clean tempered air directly into the breathing zone of the occupants. These systems have been gaining more attention in the past two decades due to their potential in improving both inhaled air quality and thermal comfort. PV systems grant individual control over air velocity, direction, and possibly temperature as well [1]. Numerous studies reported in the literature indicate that PV in combination with background total-volume systems can significantly improve the indoor environment $[2,3]$. The literature reports several variations of PV such as desk-mounted PV [3,4], ceiling-mounted PV [5,6], headset incorporated PV for use in call centres [7], headrest incorporated PV for use in theatres [8], and ductless PV [9,10]. Moreover, implementing PV can lead to substantial energy savings due to the reduction of the background total-volume ventilation system $[11,12]$.

The performance of $\mathrm{PV}$ is determined by multiple factors, such as supplied turbulence intensity, direction, diffuser type, air temperature, and air velocity [1]. Additionally, as PV systems target the breathing zone of the occupants, the interaction between the supplied air and the flow in the microenvironment surrounding the occupant is a determining factor of the performance of PV [13]. The term 'human microenvironment' was coined by Lewis et al. [14] and Clark et al. [15]. It refers to the environment in the vicinity of the human body. The outer part of the microenvironment is a layer of rising air separating exposed and clothed body parts from room air in the ambient environment; it is known as the human body convective boundary layer [13]. Due to natural convection, this layer produces mass transport of air from the lower part of the room to the breathing zone [16]; it has a significant ability to entrain and transport contaminants emitted by the human body or other sources in the ambient environment [17]. Therefore, the characteristics of the air in the convective boundary layer shape the distribution of both clean air and contaminants in the room.

The temperature difference between the surface of the human body and the adjacent air is the most influential variable on the properties of the microenvironment around the occupant. This difference in temperature determines the velocity of the flow responsible for the convective heat transfer. The higher the temperature difference, the higher the air velocity in the microenvironment and the higher the heat transfer coefficient of the body segments [18]. Other factors such as clothing, body geometry (shape and size), room ventilation, and human respiratory flow have a major influence on the thickness of the microenvironment around the human body as well [19,20]. Furniture type and arrangement such as the chair design and table positioning in front of the body are also found to have an impact on the characteristics of the microenvironment [21,22]. Additionally, body posture has a significant impact on the nature of the convective boundary layer. For a sitting person, the convective flow at the chest height is a result of the interaction between natural convection flow at the chest and the thermal plume flow from the thighs and legs of the seated person. Such flow interaction does not take place in the standing posture [21,23]. Moreover, the sitting posture shapes and alters the convective boundary layer. The peak velocity in the convective flow of sitting person leaning backward is $40 \%$ higher than what it is of a person leaning forward [21].

The human microenvironment is investigated in the literature by the means of measurements [24], visualization [25], and computational fluid dynamics simulations [26]. The literature indicates that the convective boundary layer composes a 'shield' against the invading flow of PV. Thus, by controlling its interaction with the personalized flow, the inhaled air quality can be substantially improved. According to Bolashikov et al. [27], the convective boundary layer can reduce the percentage of clean PV air in the inhaled air to $30 \%$ when PV is supplying air from the front. By breaking the convective flow using a horizontal board mounted under the desk and pressed gently against the body, the amount of clean PV air in the air inhaled could be increased to $90 \%$ (under the same boundary conditions). The same improvement in the inhaled air quality could be achieved by weakening the convective flow using a local suction box utilizing small fans under the desk. This reduces the thickness of the convective boundary layer at the face, which allows the personalized flow to reach the inhalation zone at low velocity.

This study aims to visualize the flow supplied by a desk-mounted PV system. Two methods were used to visualize the flow: rendering mass transport caused by PV and the free convection flow around the body using a schlieren mirror, and visualizing air temperature gradients between the PV opening and the manikin using a thermography camera. Both of the implemented visualization methods are not new in investigating the built environment. However, schlieren imaging is not as widely used as thermography as the number of large schlieren mirrors in the world is relatively low. Schlieren imaging is an optical method for visualizing airflow by capitalizing the refraction of light when entering a medium of different density. This refraction causes light rays to deflect from their continuous paths, creating 'schlieren' or 'streaks', which are a gradient disturbance in inhomogeneous transparent media [28]. Schlieren imaging is used in the literature to investigate a wide range of topics, such as the visualization of acoustic waves [29], gas concentrations [30], and fluid jets [31]. Furthermore, the literature reports numerous studies that implemented schlieren imaging to study the indoor environment. Using a schlieren mirror, Tang et al. [32] investigated the airflow of human exhalation in real- 
time. Their aim was to study the transmission of airborne contaminants during typical breathing scenarios such as talking and laughing. Xu et al. [33] examined the distribution of potential infections from the exhalation of standing and lying human subjects. Tang et al. [34] visualized and measured the dynamics of coughs. It was found that the maximum derived air velocity of the cough was $2.2-5.0 \mathrm{~m} / \mathrm{s}$ for females and 3.2-14 m/s for males. Tang et al. [35] used a schlieren mirror to study the impact of wearing a mask on aerosol cross contamination during coughing. Their results indicated that wearing a mask reduces the potential of cross-contamination caused by the rapid turbulent jet of the cough by blocking or redirecting the cough jet, depending on the type of mask. Further investigations of human coughing and sneezing are reported in [36].

Thermography, on the other hand, is widely used in the field of the built environment in research as well as in the practice to assess the building envelope and search for the location of thermal bridges. While thermography cameras tend to have a lower accuracy in comparison to thermistors, they offer measuring surface temperature contactless throughout an entire plane rather than the single measurement points that thermistors offer. In addition to investigating the building envelope, thermography has been utilized in the literature to investigate the indoor environment. Arghand et al. [37] implemented an infrared (IR) camera to capture the thermal distribution around the inlets of confluent jets ventilation, under-floor ventilation, and mixing ventilation. Sales et al. [38] used thermography to assess thermal comfort by capturing the surface temperature of the seat and evaluating the thermal response of various seat material to cooling and heating. Besides visualizing surface temperatures, IR cameras have been used to visualize air temperature with the assistance of an auxiliary work plane [39]. Voelker et al. [18] implemented a cardboard auxiliary work plane to visualize the convective boundary layer surrounding the human body using a thermal manikin. Cehlin et al. [40] utilized this the same technique to measure the air temperature gradient in the near zone of a low-velocity supply air terminal of displacement ventilation. In their study, a series of multiple planes were set around the supply air terminal to generate a $3 \mathrm{~d}$-image of the flow with the assistance of computer-aided design programs.

Thus, both schlieren imaging and thermography are powerful tools that can provide a detailed representation of airflow in the indoor environment. The literature review indicates that these technologies have not been implemented to investigate the performance of PV systems. Therefore, this study does not focus on the visualization process itself. Instead, it focuses on visualizing the flow supplied by PV. Flow visualization in this study aims to qualitatively investigate the nature of the supplied flow, how it behaves around the occupant, and how it interacts with the human microenvironment.

\section{Methodology}

The two visualization studies were conducted in two different laboratories; the schlieren visualization was conducted in a regular laboratory hall while the thermography investigations were conducted in a climate chamber. The schlieren visualization was not conducted in the climate chamber because the schlieren imaging system is too large to fit inside the chamber. Further details about the components of the schlieren system are reported in the following section.

\subsection{Experimental apparatus}

The schlieren imaging system at the Bauhaus-University Weimar was used in this study. The main component of the schlieren imaging system is the schlieren mirror (Figure 1); which is a single large concave spherical mirror with astronomical quality (surface accuracy = $\lambda / 9.75 @ 633 \mathrm{~nm}$, where $\lambda$ is the wavelength of light $[\mathrm{nm}])$. The diameter of the mirror is about $1 \mathrm{~m}$, which provides a large visualization area for the test field. The mirror has a focal length of $F_{s}=3001.5$ $\mathrm{mm}$ and a curvature radius of $\mathrm{R}=6003 \mathrm{~mm}$.

Besides the schlieren mirror, the schlieren imaging system consists of a light source, a knife edge, and a digital camera [41] (Figure 2). A light-emitting diode (LED) with an adjustable intensity was used as a light source ( $L_{\max }=284$ lumens). The LED light and the knife edge were placed in front of the camera at the centre of the mirror's curvature, i.e. at about $6 \mathrm{~m}$ from the mirror. As the light beam from the light source reflects from the mirror along a coincident path, it forms an image at the centre of the mirror curvature. The knife beam splitter cuts off a controlled portion of the returning light rays before entering the camera where the schlieren image is captured [28]. A 50.6-megapixel high-definition Canon EOS5DR digital camera with a $50 \mathrm{~mm} \mathrm{f} / 2.0$ lens was used in this system. The system is situated in a laboratory hall with the dimensions of $11.72 \times 6.44 \times 2.80 \mathrm{~m}$.

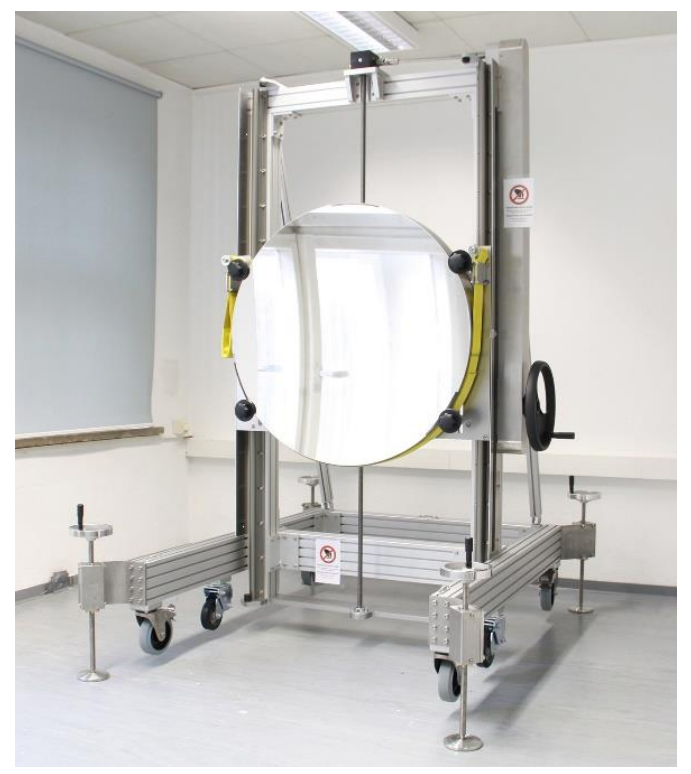

Figure 1 The schlieren mirror at the Bauhaus-University Weimar 


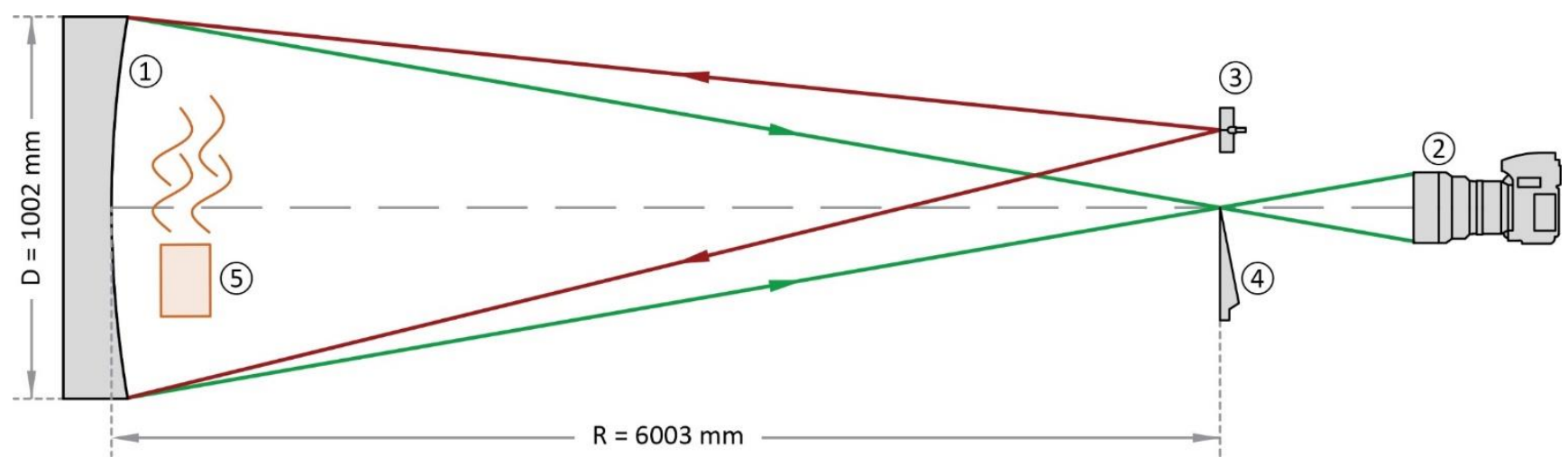

Figure 2 The components of the schlieren imaging system: (1) the schlieren mirror, (2) high-resolution camera, (3) LED light source, (4) knife edge, and (5) the test object. (reproduced from [32])

For the thermography visualizations, FLIR B400 infrared thermal camera with an accuracy of $\pm 2 \mathrm{~K}$ was used in the study. The camera has an image resolution of $320 \times 240$ pixels and $a$ measurement resolution of $0.1 \mathrm{~K}$. Thermography visualization was conducted in a $3 \times 3 \times 2.44 \mathrm{~m}$ climate chamber situated in a laboratory hall to keep it isolated from the outdoor environment. The chamber is built using insulated sandwich panels with an overall heat transfer coefficient of $U=0.27$ $\mathrm{W} / \mathrm{m}^{2} \mathrm{~K}$, which provides a high level of thermal insulation from the surrounding room. The chamber is tempered by waterbearing capillary tubing placed under the finishing layer which allows controlling the temperature of each surface separately. Moreover, the chamber could be tempered using its ventilation system, which can introduce conditioned outdoor air or recirculated air in an adjustable flow rate into the chamber.

For both visualization studies, a thermal manikin with complex male body shape was used in to simulate the thermal attributes of a human body. The manikin body consists of 22 body segments; the temperature of each body segment can be controlled separately through heating nickel wires embedded in the heat-conducting polyester body surface. The manikin is equipped with air pumps to simulate human breathing. This function was, however, not implemented in this study to simplify the experiments.

\subsection{Schlieren visualization setup}

The experimental configuration of the schlieren visualization experiments is shown in Figure 3. In this study, the manikin was left bold, naked, and seated on an open chair to allow the convective flow to move freely around the body. The manikin was placed about $45 \mathrm{~cm}$ in front of the schlieren mirror; it was operated under the 'comfort mode' to simulate the heat generation of a calm seated person. The manikin was given enough time to reach a steady surface temperature before conducting the experiments. The personalized system was placed horizontally in front of the manikin face; the distance between the manikin's nose and the personalized outlet was $40 \mathrm{~cm}$ according to the recommendations of Kaczmarczyk et al. [4] which indicate that the PV systems preferred by human subjects were located $30-45 \mathrm{~cm}$ in front of the face. Three personalized systems were tested: PV, axial fan, and a cased fan (Figure 3, b). The PV system consisted of a round opening with an inside diameter of $\varnothing 80 \mathrm{~mm}$. The flow of PV was generated by a DC centrifugal fan (a radial blower) to eliminate the swirling pattern supplied by axial fans. To achieve a calm personalized flow with no large velocity variations across the diameter of the opening, the PV system was equipped with a round honeycomb that consists of $\emptyset 8 \mathrm{~mm}$ cells with a $197 \mathrm{~mm}$ depth. The second tested system, the axial fan, consisted of a typical 7-blades PC fan with an inside diameter of $\emptyset 77 \mathrm{~mm}$. The third system, the cased fan, was achieved by adding a small round pipe in front of the axial fan (in front of the second tested system). The added pipe had a diameter of $\varnothing 76 \mathrm{~mm}$ and a depth of $50 \mathrm{~mm}$. The airflow generated by the three systems was adjusted by controlling the voltage of the fan using an electrical rectifier with an output range of 0-30 V DC.

Even though the flow visualization was the main goal of these experiments, air speed around the manikin's head was measured to complement and verify the visualization images. Air speed was measured at multiple points in three areas: between the personalized system and the face, horizontally at the head's side (at the mouth height), and vertically above the head (Figure 3, a); the spacing between the measurement points was set to $5 \mathrm{~cm}$. Air speed was measured using an Ahlborn omni-directional anemometer, which has an accuracy of $\pm 1.5 \%$ of the measured value, a measurement range of 0.01 $-1 \mathrm{~m} / \mathrm{s}$, and a response time of $2 \mathrm{~s}$. The recorded air speed is an average of the resultant scalar of the three velocity components at the measurement point over the sampling time. Each personalized system was tested twice: once with the manikin switched on and once with the manikin switched off to investigate the influence of the convective thermal layer on the personalized flow. In addition, data were recorded for each experimental case twice: measurements experiments and visualization experiments. During the measurements experiments, the personalized systems supplied an isothermal flow; i.e. at the same air temperature of the surrounding room air. On the other hand, the personalized supplied air was heated during the visualization experiments according to the concept of schlieren visualization, which is based on the difference in refraction index between mediums of different densities [28]. Therefore, the supplied personalized air needs 
(a)
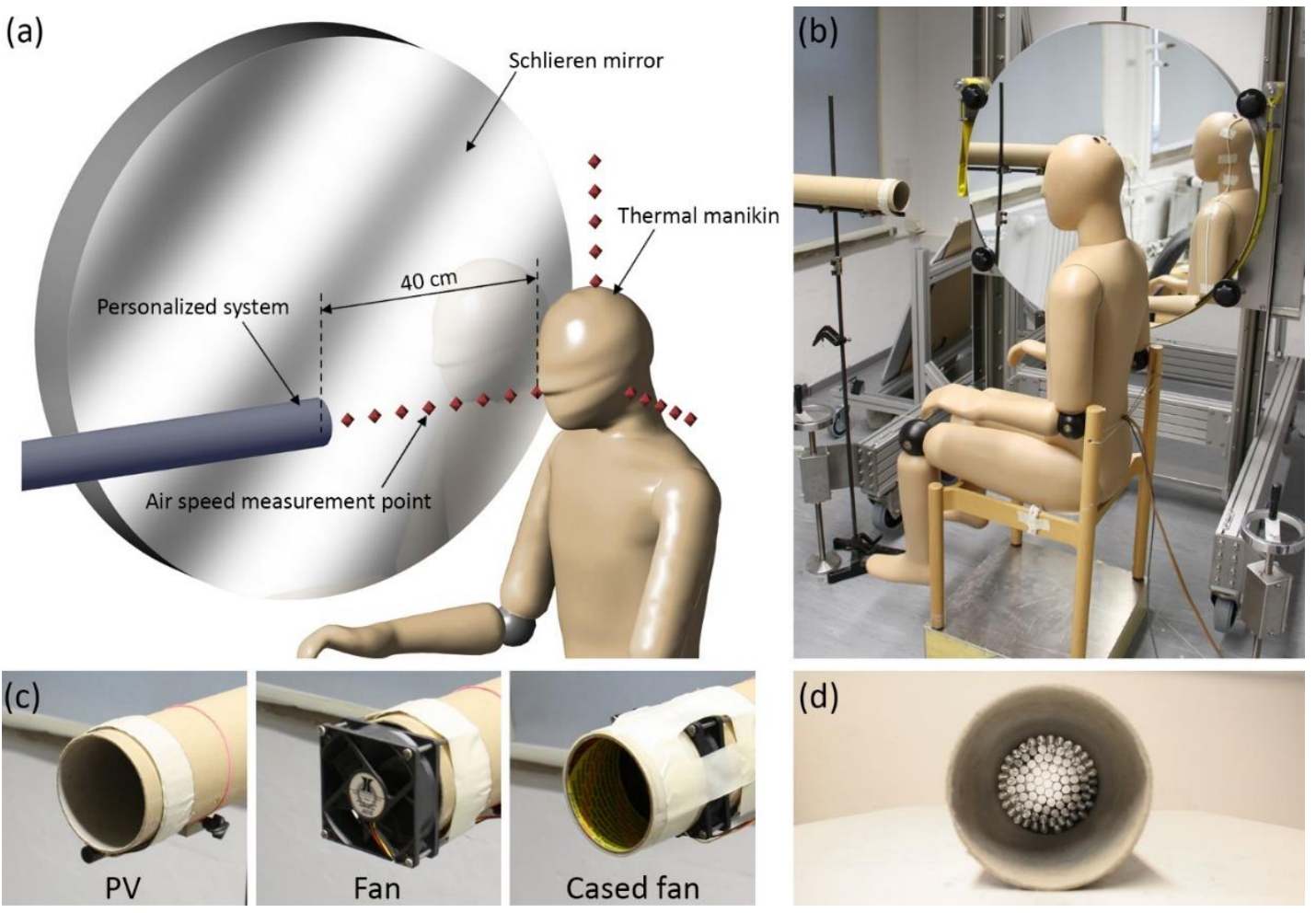

Figure 3 (a) The experimental configuration of the schlieren imaging visualization; (b) the experimental setup in the laboratory; (c) the compared systems; (d) the honeycomb at the outlet of the PV system

to have a different density from the surrounding room air to allow visualizing the flow with the schlieren mirror. As a result, all three systems (PV, fan, and cased fan) were connected to a heating box that implemented halogen lamps to heat the supplied air to an average of $33.7^{\circ} \mathrm{C}$ during the visualization experiments.

All three systems were set to $5 \mathrm{~L} / \mathrm{s}$ flow rate during all tested cases. During all the experiments, the heating system in the laboratory room was switched off to provide a quiescent ambient atmosphere. To investigate the temperature stratification in the room, the air temperature was monitored approximately at the centre of the room at four levels: 0.1, 0.6, 1.1, $1.7 \mathrm{~m}$, which corresponds to the heights of ankles, knees, head of a seated occupant, and head of a standing occupant according to the ISO 7726 standard [42]. Air temperature measurements were conducted using Ahlborn NiCr-Ni thermocouple sensors with an accuracy of $\pm 0.05 \mathrm{~K} \pm 0.05 \%$ of the measured value.

Multiple camera settings were tested before conducting the visualization experiments. According to the test images, an $\mathrm{f}$ stop of f/2, a focal length of $135 \mathrm{~mm}$, and an ISO speed of 800 were used to achieve the highest possible contrast in the schlieren images while showing as many details as possible. Further used settings included a $50 \mathrm{fps}$ frame rate and a shutter speed of $1 / 200$. The image size was set to a high value of $8688 \times 5792$ pixels to capture high definition images. Moreover, the LED light source was set to its maximum value (284 lumens) to yield well-lit images.

For image analysis, the captured schlieren images were then imported into the numerical computing environment Matlab to generate the flow vectors using the Farnebäck algorithm. This algorithm implements the polynomial expansion concept, which estimates a quadratic polynomial neighbourhood for each pixel to estimate the displacement of the pixels between consecutive schlieren images [43]. The generated vectors were used to evaluate the direction and velocity of the flow.

\subsection{Thermography visualization setup}

For the thermography visualization, one workstation set-up was arranged inside the climate chamber consisting of one desk equipped with a desktop computer with two screens, and an occupant that was simulated using the thermal manikin seated on an open chair. The workstation was equipped with a personalized ventilation system (PV) with a round diffuser (opening diameter $\mathrm{D}=7.5 \mathrm{~cm}$ ). Similar to the schlieren visualization set-up, the PV outlet was located $40 \mathrm{~cm}$ from the manikin's nose (Figure 4).

Since the infrared camera can only detect the temperature of surfaces, not air temperature, an auxiliary work plane was used. According to the recommendations of Voelker et al. [18] and Cehlin et al. [40], a work plane constructed from corrugated cardboard sheets was built between the manikin the PV outlet (Figure 4, a). The $6 \mathrm{~mm}$ sheets are physically stable which eliminated the need for extra supports that could interfere with the flow. Furthermore, they have a low thermal capacity; thus, the surface temperature of the sheets reached the same temperature as the surrounding air in a short time. The smooth, brown sheets have an emissivity of $\varepsilon=0.81$. This relatively high emissivity is recommended to reduce the effects of reflective surroundings during the measurements 

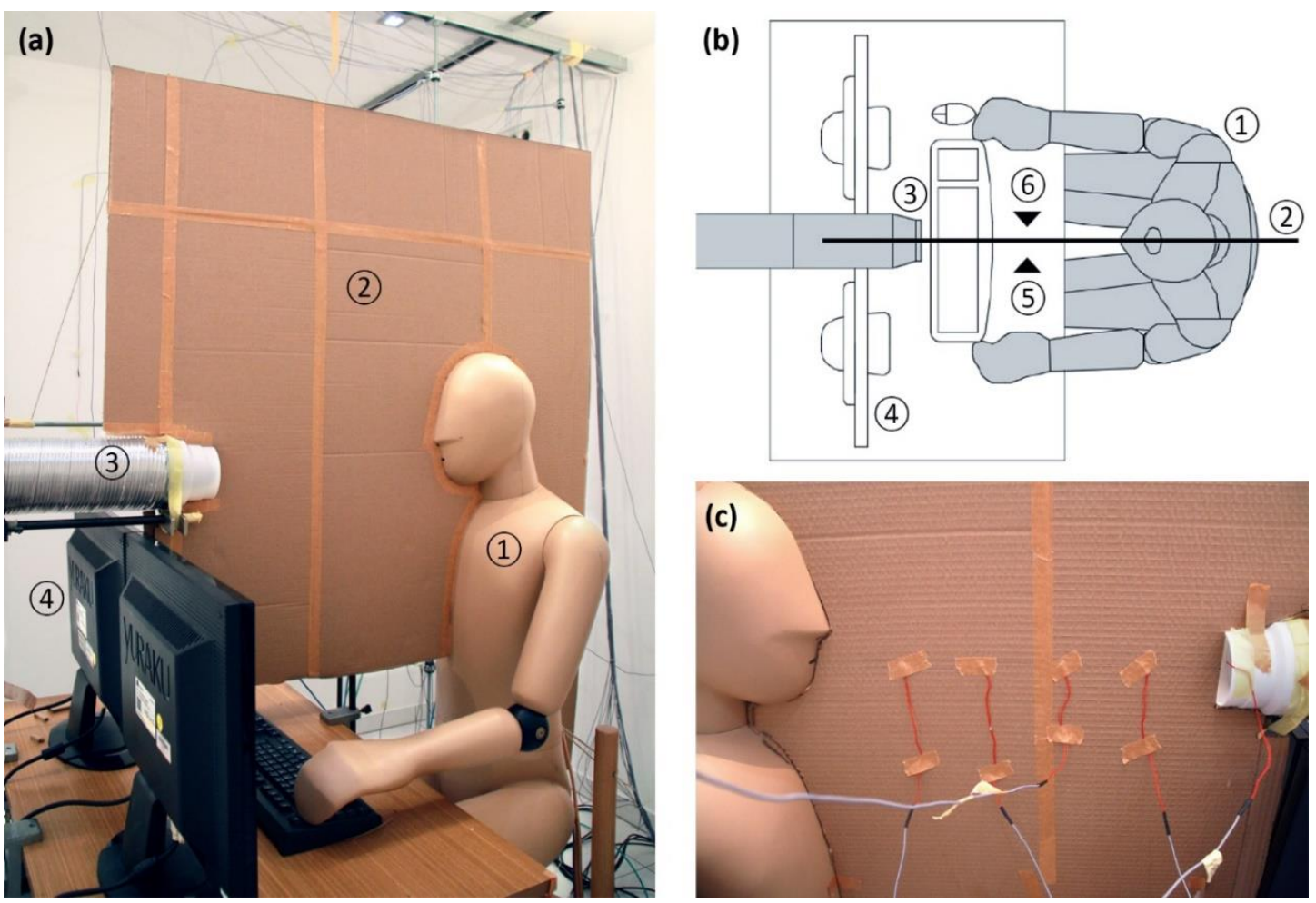

Figure 4 (a) and (b): the experimental configuration in the chamber: (1) the thermal manikin, (2) the auxiliary work plane at the symmetry axis of the set-up, (3) PV outlet, (4) computer screens, (5) the camera facing side of the plane, and (6) the surface temperature sensors side (backside) of the plane; (c) the backside of the work plane on which surface temperature sensors were mounted

[18]. In order to facilitate building the work plane around the curvature of the manikin body, the manikin was left bold and naked in this study.

To check the temperature in the thermogram, four negative temperature coefficient thermistors (NTC) with an accuracy of $\pm 0.05 \mathrm{~K}$ of the measured value were mounted on the work plane at $8 \mathrm{~cm}$ spacing between the PV outlet and the manikin's face. Since the work plane was built at the symmetry axis of the manikin and the workstation, the sensors were mounted on the cardboard side facing away from the manikin in order to avoid the sensors appearing in the flow visualizations images (Figure 4, c). Implementing these sensors was necessary to ensure the accuracy of the thermal images since the absolute error of the thermography camera is $\pm 2 \mathrm{~K}$. Before each visualization case, the climate chamber was given enough time to reach a steady state. When a steady state was achieved, data was recorded and averaged from the NTC sensors for 30 minutes with a sampling interval of $t=5 \mathrm{~s}$. Afterwards, a person went inside the chamber to take the thermography image.

The visualization was conducted under two room air temperature settings $\theta_{\mathrm{a}}=26$ and $28^{\circ} \mathrm{C}$. The air temperature at the PV outlet was cooler than the room air temperature by an average of $2.5 \mathrm{~K}$. The chamber was tempered using a background mixing ventilation system and a personalized ventilation system. In other words, the temperature control function of the chamber interior surfaces was switched off. The total ventilation flow rate was set to $\dot{V}=32 \mathrm{~L} / \mathrm{s}$ using two variations: $\dot{\mathrm{V}}_{\mathrm{MV}}=28 \mathrm{~L} / \mathrm{s}$ with $\dot{\mathrm{V}}_{\mathrm{PV}}=4 \mathrm{~L} / \mathrm{s}$, and $\dot{\mathrm{V}}_{\mathrm{MV}}=27 \mathrm{~L} / \mathrm{s}$ with $\dot{\mathrm{V}}_{\mathrm{PV}}=5 \mathrm{~L} / \mathrm{s}$. These two settings resulted in air speed values measured at the manikin's face of $\mathrm{v}_{\mathrm{a}}$ face $=0.36 \mathrm{~m} / \mathrm{s}$ and 0.66 $\mathrm{m} / \mathrm{s}$ respectively. Additionally, reference cases with no PV were also investigated and compared to the cases with PV. Thus, a total of six cases were tested: (1) $\theta_{a}=26^{\circ} \mathrm{C}$, no PV; (2) $\theta_{\mathrm{a}}=26^{\circ} \mathrm{C}, \mathrm{v}_{\mathrm{a}, \text { face }}=0.36 \mathrm{~m} / \mathrm{s}$; (3) $\theta_{\mathrm{a}}=26^{\circ} \mathrm{C}, \mathrm{v}_{\mathrm{a}, \text { face }}=0.66 \mathrm{~m} / \mathrm{s}$; (4) $\theta_{\mathrm{a}}=28^{\circ} \mathrm{C}$, no PV; (5) $\theta_{\mathrm{a}}=28^{\circ} \mathrm{C}$, $\mathrm{va}_{\mathrm{a} \text {,face }}=0.36 \mathrm{~m} / \mathrm{s}$; and (6) $\theta_{\mathrm{a}}=$ $28^{\circ} \mathrm{C}, \mathrm{Va}$, face $=0.66 \mathrm{~m} / \mathrm{s}$.

\section{Schlieren imaging results}

\subsection{Visualization results}

During the visualization experiments, air temperature measurements showed that all the cases were tested in an ambient temperature with a relatively small vertical stratification. The average temperature difference between 0.1 and $1.1 \mathrm{~m}$ was $1 \mathrm{~K}$ during the tested cases; whereas the average difference between 0.1 and $1.7 \mathrm{~m}$ was $1.2 \mathrm{~K}$. Average room temperature was $22.7^{\circ} \mathrm{C}( \pm 0.9 \mathrm{~K})$, which is $11 \mathrm{~K}$ cooler than the average air temperature supplied by the personalized systems during the visualization experiments. As mentioned earlier, such high temperature gradient was necessary to capture detailed schlieren images.

The results of the visualization experiments are shown in Figures 5 and 6 . While Figure 5 shows the schlieren images of the tested systems, Figure 6 illustrates the flow vectors generated using Farnebäck algorithm in Matlab. The length of 


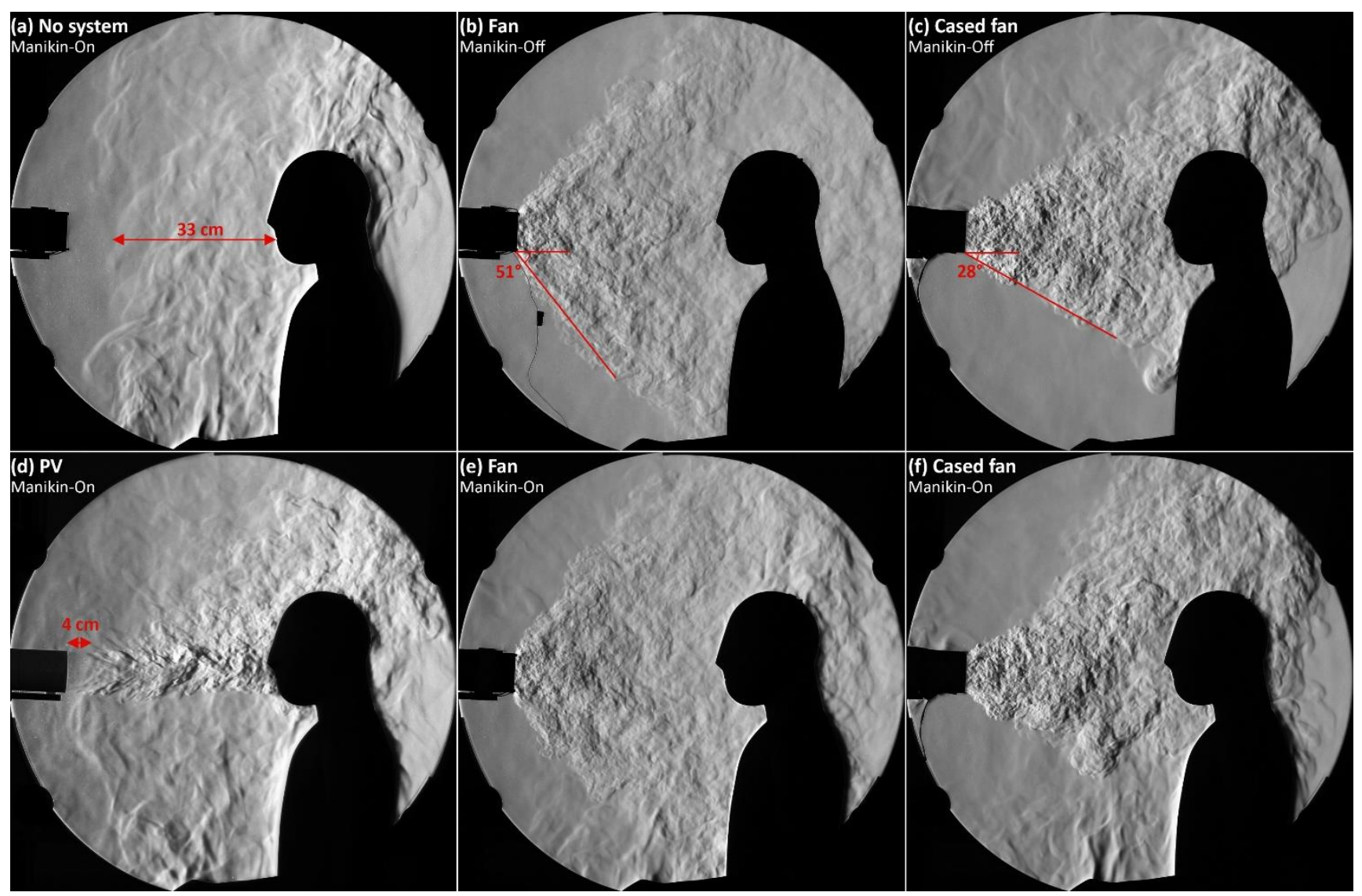

Figure 5 Schlieren images of the tested personalized systems with the manikin switched on and off
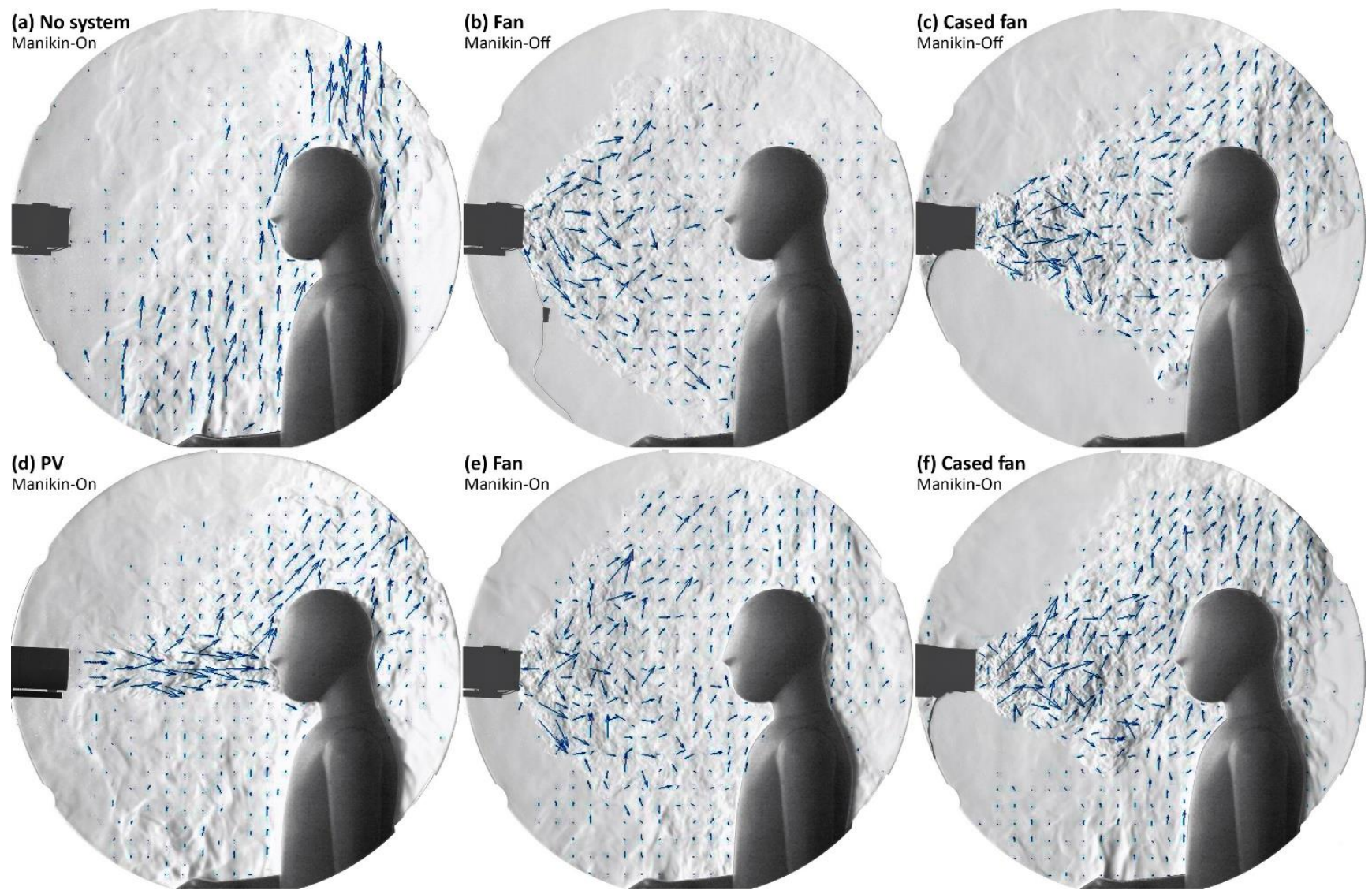

Figure 6 Flow vectors generated from the schlieren images using the Farnebäck algorithm. The vectors in image (d) are $x 4$-enlarged as they were highly small due to low velocity values compared to the other five images 
the vectors responds to their velocity value; i.e. the longer the vector the higher the velocity. However, these vectors express qualitative data. In other words, the length of the vectors does not correspond to a certain scale that could be used to quantify the velocity values. Research is currently being conducted in the Bauhaus-Universität Weimar to develop a Matlab algorithm that can accurately quantify velocity values from the schlieren images.

The schlieren images indicate a remarkable difference in flow patterns supplied by the three systems. When no system was used, the manikin was encased in a layer of convective flow with different air temperature and velocity from the surrounding air. This layer created a shield of ascending air in front of the manikin; the thickness of this air shield under the implemented experimental conditions was about $33 \mathrm{~cm}$ (under the implemented boundary conditions, body posture, clothing level, manikin operating mode, etc.). The maximum strength of the convective flow was above the horizontal surfaces, such as the top of the head and the thighs (Figure 5, a). The flow vectors in Figure 6 (a) indicated that the convective flow followed the curvature of the head at the forehead, likely due to the Coandă effect. Eventually, the ascending flow from the face and the back of the head met and formed a column of air moving upwards above the backside of the head creating a thermal plume.

The convective 'air shield' was largely impacted and disturbed by all three systems (PV, fan, and cased fan). PV, on one hand, supplied a steady low-turbulence flow that exited the PV opening in a laminar stream; the PV flow transitioned to a higher turbulence intensity, becoming visible after about $4 \mathrm{~cm}$ from the PV opening (Figure 5, d). The PV flow had a relatively high source and target velocity; this enabled the flow to fully penetrate the convective boundary layer to deliver clean air and induce air movement at the targeted body segment; i.e. the face. However, the convective flow was still able to push the PV flow upwards, which caused the supplied flow to slightly curve up towards the upper half of the face. Another reason for this flow behaviour is that the personalized flow had to be heated to allow visualizing it using the mirror as explained in Section 2.2. Therefore, the personalized flow slowly moved upwards due to its lower density compared to room air.

On the other hand, the axial fan supplied a turbulent flow with a wide spreading angle of $51^{\circ}$, creating a flow field with a conical frustum shape that has a wide base radius which is about 12 times larger than the top radius (the top radius is the fan radius in this case). This wide-angle diffused the supplied flow over a large target area and reduced the target velocity (Figure 5, b and e). The high turbulence intensity of the fan-supplied flow can be noticed in the varied directions and lengths of the flow vectors in Figure 6 ( $b$ and e). When the manikin was switched off, the fan-induced flow was able to reach the manikin's body providing elevated air velocity around the abdomen, chest, upper arms, and head (Figure 5, b). Thus, when thermal comfort is in question, the axial fans can provide a wider target range in comparison to $\mathrm{PV}$.
However, the schlieren images suggest that the fan was supplying air with a fairly constant velocity across the diameter, whereas additional measurements using hot-wire anemometers revealed that the highest air velocity values were at the perimeter of the fan; i.e. the surface of the frustumshaped flow field had the highest velocities. Moreover, the anemometer measurements showed that the velocity drops significantly at the centre of the fan where the motor was located. The reason behind this discrepancy between the visualized and measured flows is that the schlieren image is a two-dimensional projection of the three-dimensional flow field. Thus, the schlieren image shows all the layers of the flow's conical frustum rather than providing information about the core of the flow.

When the manikin was switched on, the convective flow around the manikin mixed with the fan-supplied flow. This reduces the supplied velocity and prevented the supplied flow from reaching the manikin's body (Figure 6, e). This indicates that the axial fan requires a higher flow rate to supply a flow strong enough to penetrate the convective boundary condition in comparison to $\mathrm{PV}$, which makes $\mathrm{PV}$ a preferable option to provide clean air into the breathing zone.

When adding a short duct to the fan, i.e. converting it into a cased fan, the spread angle of the tested system was reduced to $28^{\circ}$ (Figure 5, c). This concentrated flow was more successful in penetrating the convective boundary layer compared to the axial fan. Yet, the convective flow from the thighs, pelvis, and chest was strong enough to prevent the flow of the cased fan from reaching the chest (Figures 5 and 6, f). Yet, converting the fan into a cased fan greatly increased the turbulence intensity of the supplied flow as the fan was swirling the air against the walls of the pipe. The increased turbulence intensity could be observed as a noticeable increase in the roughness of the flow frustum in the schlieren images compared to the fan-generated frustum and the increased density of the flow vectors and the arbitrariness of their directions (Figures 5 and 6, e and f). The rough texture of the cased-fan-generated frustum was lower when the manikin was switched off due to the absence of interfering ascending flow (Figure 5, c). In this case, the flow supplied by the cased fan was able to reach the manikin's head, neck, and chest.

\subsection{Measurements results}

The measured values confirm the observations acquired from the qualitative analysis of the visualization cases. As shown in Figure 7 (a), even though the three compared systems supplied air with the same flow rate, only the flow of PV was able to maintain its air speed until reaching the manikin's face. When the manikin was switched off, the air speed value was almost similar at the PV opening and the manikin's face. Yet, when switching the manikin on, the free convective flow encasing the manikin resisted the supplied personalized flow and slowed it by $\Delta \mathrm{v}_{\mathrm{a}}=0.26 \mathrm{~m} / \mathrm{s}$ compared to its initial value. However, the PV system still achieved the highest target speed among the other cases when the manikin was switched on, which was $0.71 \mathrm{~m} / \mathrm{s}$ at the face. Contrarily, 

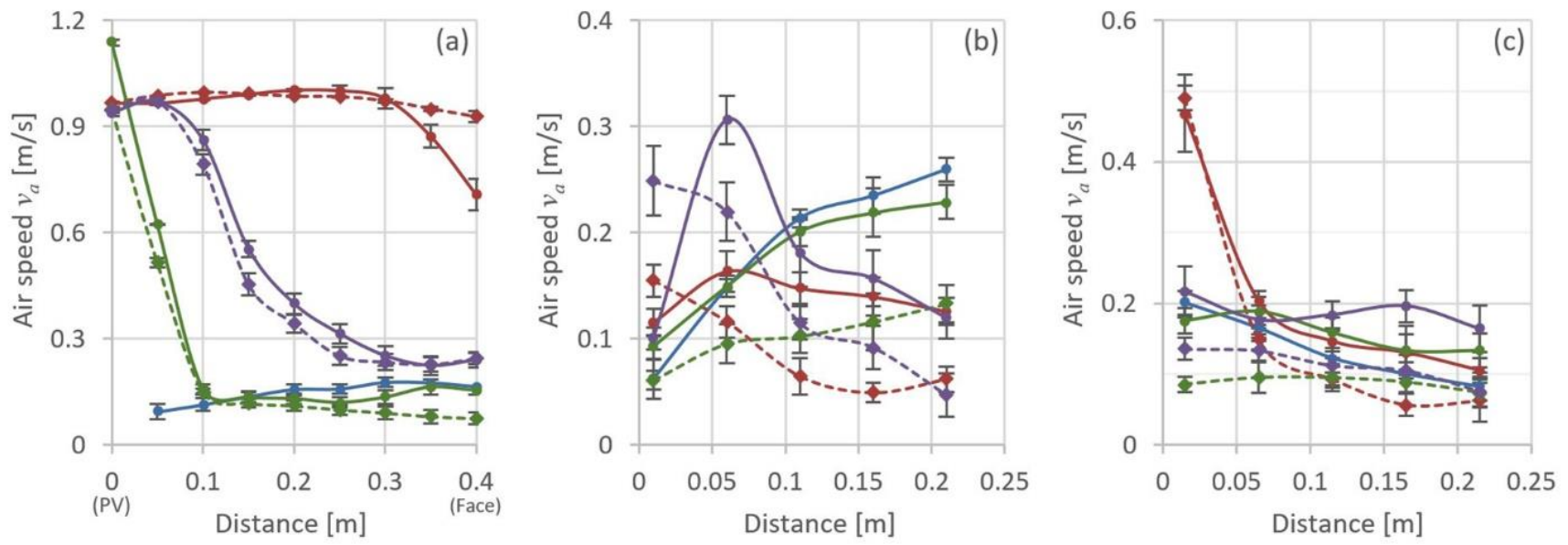

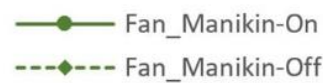

$\longrightarrow$ Cased fan_Manikin-On

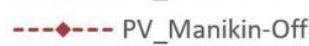

----- Fan_Manikin-Off

------Cased fan_Manikin-Off

Figure 7 Measured air speed (a) in the flow field between the personalized systems and the manikin's head, (b) vertically above the manikin's head, and (c) horizontally on the side of the manikin's head. The measurements fluctuations are plotted as error bars indicating the standard deviation

the axial fan diffused the air over a large area with a large spread angle, which led to a significant drop in air speed at 10 $\mathrm{cm}$ in front of the fan and a remarkably low air speed at the manikin's face. This applies regardless of whether the manikin was switched on or off. Nevertheless, when the manikin was on, the target speed at the face was higher compared to the case in which the axial fan was used with the manikin switched off; i.e. opposite to the behaviour noticed during the PV cases. This recorded higher speed $(0.15 \mathrm{~m} / \mathrm{s})$ is originated in fact from the free convective flow, not from the air supplied by the axial fan. Similar speed values were recorded in the vicinity of the manikin's face during the 'No personalized system' case in which the manikin alone was switched on. On the other hand, the flow from the cased fan disturbed the free convective flow and yielded an air speed value at the face of $0.24 \mathrm{~m} / \mathrm{s}$, which is considerably lower than what PV resulted in at the face. Nevertheless, the cased fan achieved a higher air speed at the face compared to the axial fan. This is because the attached pipe in the cased fan avoided the central dead-eye zone typical for axial fans since the extra ducting down flow of the fan resulted in reshaping the flow.

Figure 7 (b) exhibits the air speed values recorded vertically above the manikin's head during the measurements experiments. It shows that when no personalized system was used, the air speed directly above the head was fairly low $(0.06$ $\mathrm{m} / \mathrm{s}$ ), which indicates that the measurement point fell within the so-called dead zone above the head below the convergence zone of the rising flow that broke off behind the maximum thickness of the head [44]. The air speed continued to increase as the vertical distance from the head increased, which agrees with the findings of Voelker et al. [18]. This pattern appeared during the axial fan cases as well. When the manikin was switched on, the air speed above the head was relatively high and nearly equal to what it was when no personalized system was used. This is because the fan diffused the air over a large area and was not able to destroy the convective boundary layer. In contrast, when the manikin was switched off, air speed was remarkably lower above the head as there was no thermal plume and the supplied flow from the fan was hardly able to reach this zone. On the other hand, the focused flow of $\mathrm{PV}$ resulted in an elevated air speed in the first five centimetres above the head; then the speed dropped as the vertical distance from the head increased, especially when the manikin was switched off. The cased fan cases dissipated the thermal plume as well and resulted in a lower air speed as the vertical distance above the head increased. Yet, interestingly, the cased fan achieved the highest air speed in the first two measurement points. This can be explained due to the larger target area of the cased fan in comparison to PV.

Air speed on the side of the head, on the other hand, showed different patterns than the values recorded above the head. As shown in Figure 7 (c), when no personalized system was used, the air speed directly on the side of the head was 0.2 $\mathrm{m} / \mathrm{s}$. Due to free convection, this value dropped to $0.1 \mathrm{~m} / \mathrm{s}$ at $16 \mathrm{~cm}$ from the head, which is the distance to which the shoulder extends from the head. The speed further dropped to $0.08 \mathrm{~m} / \mathrm{s}$ at the last measurement point, which had a $5 \mathrm{~cm}$ displacement from the edge of the shoulder. The axial fan (with the manikin on and off) only slightly altered the air speed on the side of the head. The cased fan had a larger impact; it resulted in an air speed of up to $0.2 \mathrm{~m} / \mathrm{s}$ at $16 \mathrm{~cm}$ horizontally from the head. PV, on the other hand, had the largest influence of speed on the side of the head. PV resulted in an air speed as high as $0.49 \mathrm{~m} / \mathrm{s}$ recorded at $6 \mathrm{~cm}$ from the head, which is remarkably higher than the speed recorded above the head. This is resulted by the manikin's face area targeted by PV and by the geometry of the manikin's head. The PV target was the manikin's nose and the area around it, which is not located in the vertical centre of the face, but rather shifted downwards towards the chin. Additionally, the manikin's head is not fully round; its height is larger than its width $(\mathrm{H}=22.5 \mathrm{~cm}, \mathrm{~W}=14.5$ $\mathrm{cm}$ at the nose level). Therefore, the distance between the 
centre of the flow target (the nose) and the vertical measurement points was $21.5 \mathrm{~cm}$, while it was $17.5 \mathrm{~cm}$ to the horizontal measurements points. Finally, the curvature of the head geometry is almost parallel to the flow on the head sides, whereas the curvature is partially perpendicular to the flow as the supplied air moves upwards towards the top of the head. All these factors contributed to lessening the momentum on the top of the head, while allowing the flow to maintain its speed on the side of the head.

\section{Thermography visualization results}

As discussed in the Methodology section, an auxiliary work plane was used to visualize the air temperature. Cehlin et al. [40] report that the influence of such impervious plane on the flow is negligible when the direction of the plane is parallel to the flow at low speed. The conducted tests showed that even with the relatively high speed of the personalized ventilation system, the NTC and thermography results showed good agreement. The average difference between the thermography and NTC measurements were always below the maximum uncertainty value of $1.0 \mathrm{~K}$ reported by Cehlin et al. [40] as shown in Figure 8, in which the shaded area represents the maximum $\pm 2 \mathrm{~K}$ measurement uncertainty of the IR camera. The error bars plotted at the measurement points indicate the standard deviation of the recorded data, which represents the fluctuation of the measurements over time. During all the studied cases, the NTC measured values fell within the uncertainty range of the camera.

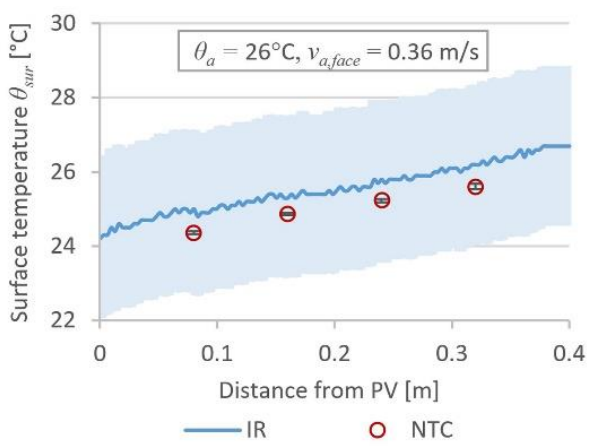

Figure 8 Air temperature between the PV outlet and the manikin's face under the boundary conditions of $\theta_{a}=26^{\circ} \mathrm{C}$, $v_{a, f a c e}=0.36 \mathrm{~m} / \mathrm{s}$ as an example. The shaded area represents the measurement uncertainty of the IR camera

Measurements and thermal images analysis indicated that besides defining the emissivity factor, defining the environmental variables accurately in the camera had a vital effect on the accuracy of the results. The conducted experiments showed that air temperature and reflective temperature had the largest influence. Therefore, these parameters need to be closely monitored during the recording. When estimating the reflective temperature, it was important to account for the surface temperature of the person taking the picture. Furthermore, the surface temperature of all the surfaces facing the camera should be considered as well. More accurate result might be reached using a remotely controlled thermography camera with which the user does not have to enter the climate chamber to take the picture.

Figure 9 shows the thermography images for studied cases illustrating the different air temperatures in the thermogram between the PV outlet the manikin's body. Since the main point of interest is the interaction between the flow from PV and the manikin's thermal boundary layer, the temperature scale range was chosen to accommodate the clearest possibility. Therefore, the $\theta_{\mathrm{a}}=26^{\circ} \mathrm{C}$ cases have a different temperature scale range than the $\theta_{a}=28^{\circ} \mathrm{C}$ cases. The elevated temperature at the lower left corner of the images is caused by computer screens, which indicates that even flat screens have a considerable influence on the indoor environment.

During the 'no PV' cases, the corona-shaped thermal boundary layer around the manikin's body is clear and undisturbed. It merges with the convective flow generated by the computer screens in front of the manikin. The air at the manikin's nose was relatively warm. When the PV system was employed, the ascending warm airflow between the PV and the manikin was interrupted. The airflow from the PV is fully penetrating the thermal plume. Thus, the inhalation air temperature is significantly lower, which agrees with the recommendations reported in [45] that advocates supplying cool, clean, dry air for the inhalation. Increasing the target air speed from $0.36 \mathrm{~m} / \mathrm{s}$ to $0.66 \mathrm{~m} / \mathrm{s}$ had a minor effect on the temperature gradient between PV and the manikin face since both target velocities fully penetrated the manikin's microenvironment. Moreover, the invading flow from the PV weakened the thermal plume above the manikin's head, thus changing the air distribution around the body $[13,24]$. Due to the uncertainty of the climate chamber control system, the PV air temperature was slightly warmer during the $\theta_{a}=28^{\circ} \mathrm{C}$, $\mathrm{V}_{\mathrm{a}, \text { face }}=0.66 \mathrm{~m} / \mathrm{s}$ case compared to the $\theta_{\mathrm{a}}=28^{\circ} \mathrm{C}$, $\mathrm{v}_{\mathrm{a}, \text { face }}=0.36$ $\mathrm{m} / \mathrm{s}$ case. This slight difference can be noticed by comparing the two $\theta_{a}=28^{\circ} \mathrm{C}$ PV cases in Figure 9 .

Besides influencing the air distribution around the body, PV affected the surface temperature of the manikin. Figure 10 illustrates this effect through changing temperature scale range in order to accommodate for the surface temperature. When the PV system was not used, the manikin face had a surface temperature close to the other body segments. Implementing the PV system decreased the surface temperature by up to $2.7 \mathrm{~K}$ during the $\theta_{\mathrm{a}}=26^{\circ} \mathrm{C}$, $\mathrm{va}_{\mathrm{a}}$,ace $=0.66$ $\mathrm{m} / \mathrm{s}$ case. Since thermal sensation is a result of offsetting the skin temperature from a neutral set point $[46,47]$, the PV system can improve local thermal sensation at the head as well as overall thermal sensation since the latter is a function of the local sensation of the different segments of the human body $[46,48]$. This improves thermal comfort since the head is a highly sensitive segment to discomfort in warm indoor air temperatures [49].

Additionally, this change in local surface temperature can be perceived as pleasurable since it is pushing the surface temperature towards the cool side of the thermal sensation scale in a warm environment, thus accommodating the needs 

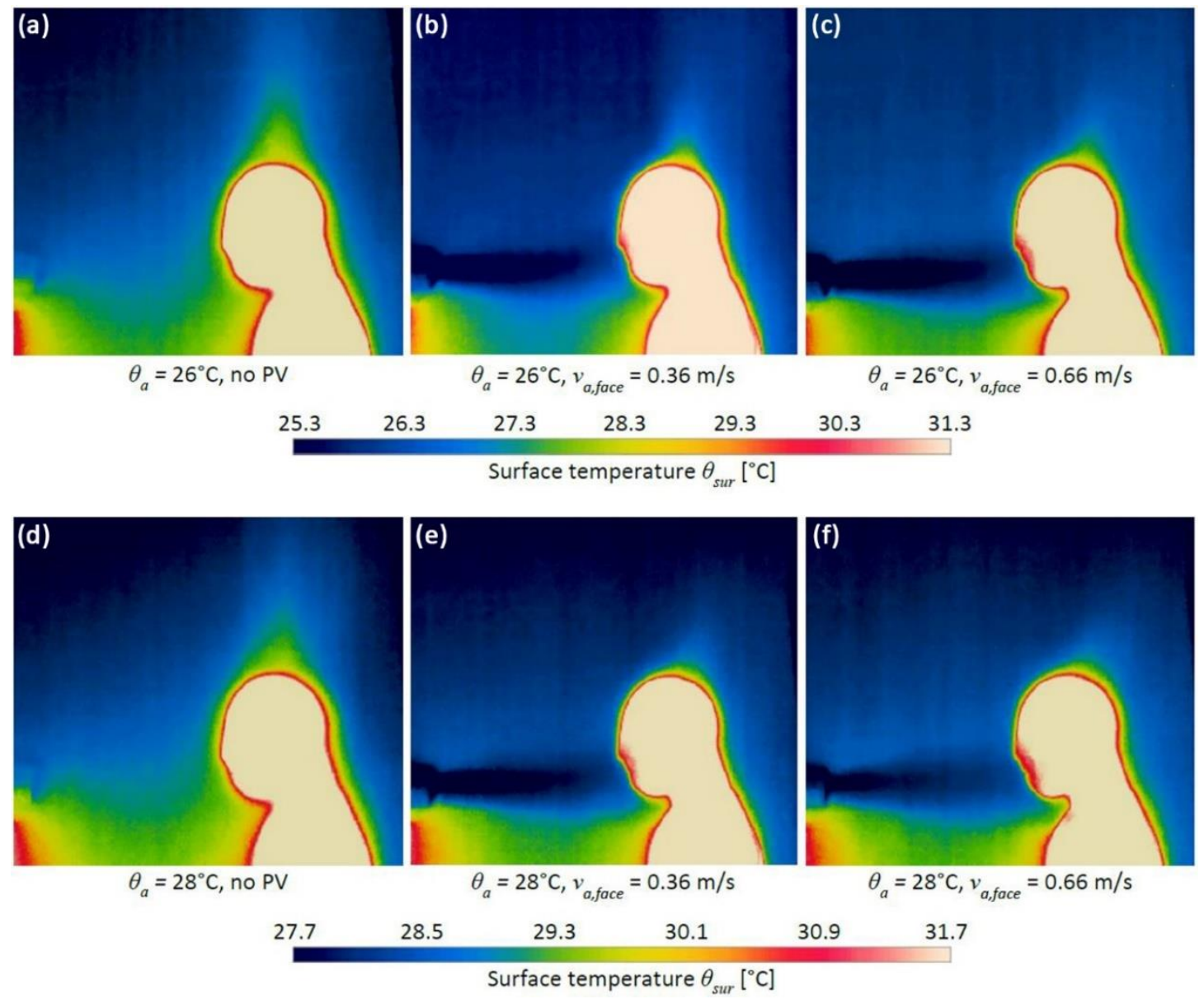

Figure 9 Thermography images of the work plane under the tested boundary conditions

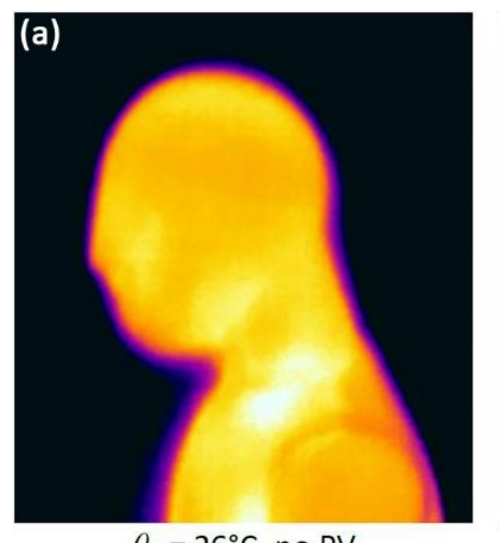

$\theta_{a}=26^{\circ} \mathrm{C}$, no PV

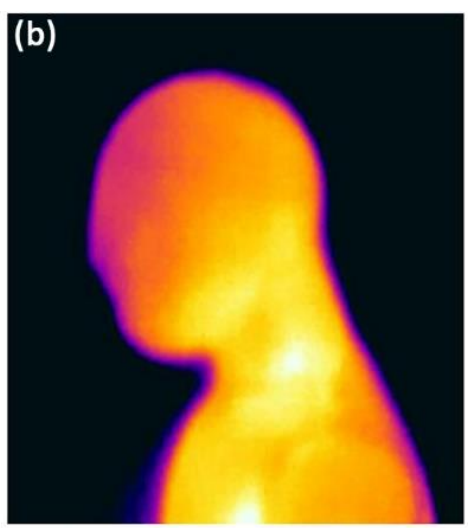

$\theta_{a}=26^{\circ} \mathrm{C}, v_{a, f a c e}=0.36 \mathrm{~m} / \mathrm{s}$

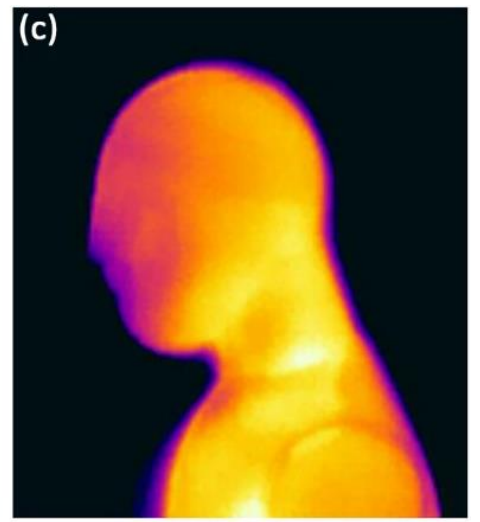

$\theta_{a}=26^{\circ} \mathrm{C}, v_{a, f a c e}=0.66 \mathrm{~m} / \mathrm{s}$

$29 \quad 30$

31

32

33

34

35

Surface temperature $\theta_{\text {sur }}\left[{ }^{\circ} \mathrm{C}\right]$

Figure 10 The influence of the PV system on the face surface temperature

of the human thermoregulation system. This sensation is called 'sensory pleasure' [50], and it is caused by a phenomenon called alliesthesia. Alliesthesia evinces that when the body is exposed to a certain stimulus, a sensation of pleasure or displeasure can occur according to the general state of the body [51]. Thus, when a subject seated in a thermal uncomfortable environment receives a thermal stimulus in the desired direction, the subject can experience a thermal overshoot that is more pleasurable than the neutral state [52]. Since the PV system targets a single body part, it can yield spatial alliesthesia, where the local thermal sensation of the body segments falls on both sides of the neutral sensation. Yet, under the correct combination of thermal sensations, it can 
result in a sensation more pleasurable than when the whole body is experiencing neutral thermal state [53].

\section{Discussion}

Figure 11 compares the human body boundary layer with a thermal image and the schlieren image. The temperature scale in the thermography image was adjusted to exhibit the temperature gradient around the body instead of PV, which was the main focus in Figure 9. The resulted images indicate a difference between the distribution of air temperature and airflow around the body. However, conducting the experiments in different rooms with slightly but unavoidable different boundary conditions might have played a big role in differentiating the resulted boundary layers. Moreover, the IR camera captured rather a steady-state condition due to the heat transfer to the auxiliary work plane and its heat capacity while the schlieren image shows a snapshot of the transient convective flow around the body.

With consideration of the above-mentioned inaccuracies, Figure 11 presents two variations of the boundary layer around the body: a temperature-defined boundary layer and an airflow-defined boundary layer, which agrees with the findings reported in [44]. The temperaturedefined layer is generally thicker than the airflow layer, especially at the manikin's back. The air temperature has the highest value at the manikin surface. The temperature value drops gradually as the distance from the surface increases until reaching the temperature of the surrounding undisturbed ambient air. The airflow-defined layer, on the other hand, starts with a $v_{a}=0 \mathrm{~m} / \mathrm{s}$ at the manikin surface because of the shear stress. The velocity value increases with increasing distance from the surface until reaching a maximum value that depends on the boundary conditions. Thereafter, the velocity value drops into the velocity of the ambient air.

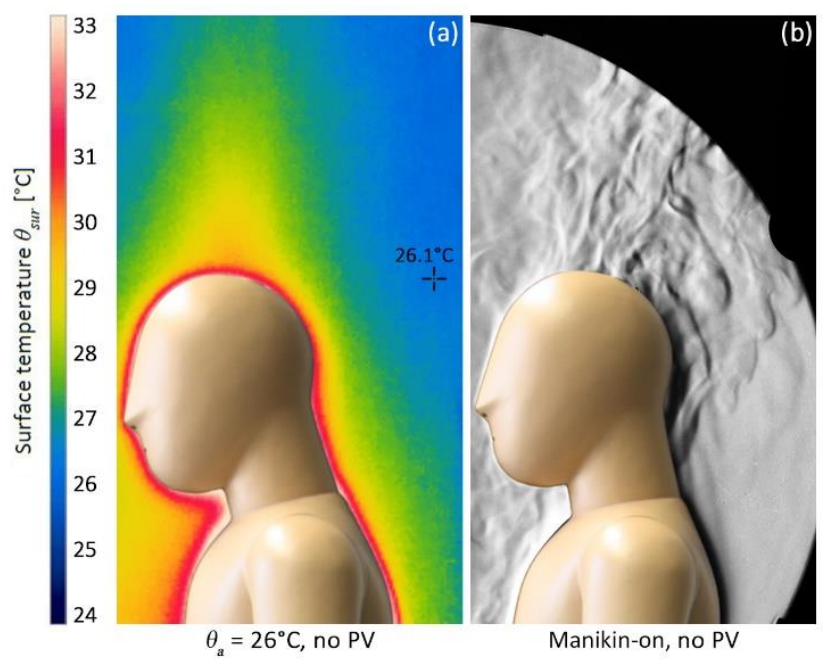

Figure 11 The microenvironment around the body when no personalized system is used. The crosshair in the thermography image marks the temperature of the undisturbed room air
The distinction between the two boundary layers is important when examining different aspects of the quality of the indoor environment. The airflow layer is more important for inhaled air quality as it defines the transport of contamination from the lower part of the room into the breathing zone. Moreover, the strength of the flow in this layer determines the required velocity of the invading flow needed to deliver clean air for inhalation. Numerous factors establish the strength of the airflow-defined layer, such as clothing, body geometry, ventilation, and respiration. On the other hand, the temperature layer plays a big role in determining thermal comfort, both overall (for the whole body) and local (for each body segment). The thickness of this layer decides the location from which air temperature is taken around each body segment to accurately calculate thermal sensation. This could be achieved through the coupling of computational fluid dynamics and thermal regulation models to automatically determine the thickness of this layer for a given set of boundary conditions [26].

\section{Conclusions and limitations}

Flow visualization is an important tool to thoroughly understand the nature and behaviour of the flow. Two visualization methods were used to visualize the personalized flow in this study: schlieren imaging to visualize air velocity and turbulence intensity; and thermography to visualize air temperature gradients.

The schlieren imaging visualization showed that there is a remarkable difference between the flow pattern supplied by PV, axial fans, and cased fans. While PV provided a lowturbulence steady flow that successfully penetrated the convective boundary layer surrounding the body, the axial fan diffused the supplied air over a large target area with high turbulence and velocity variations across the diameter. Therefore, even though the fan supplied a flow rate similar to that of the PV, it only disturbed the convective boundary layer rather than destroying it. The cased fan was a middle point between the two systems. While the added duct in the cased fan cases concentrated the flow and reduced the target area which allowed supplying more air into the breathing zone compared to the fan, it considerably increased the turbulence intensity of the supplied air.

Thermography visualization showed that the coronashaped thermal boundary layer surrounding the body is dissipated and penetrated by the supplied cool personalized air. Additionally, the supplied air cooled the surface temperature of the face, which indicates the large impact of PV on local thermal sensation and comfort. Additionally, targeting one body part suggests inducing spatial alliesthesia, which can increase satisfaction with the thermal environment.

This study encountered a number of limitations that should be considered when planning for future investigations. The main limitation was that the schlieren imaging system is too large to be placed inside the climate chamber, which led to performing the schlieren experiments and the thermography experiments in two different rooms, thus resulting in a 
separation between the schlieren and the thermography visualization studies. Additionally, conducting the schlieren visualization in a laboratory hall instead of a climate chamber restricted the consistency of the boundary conditions under which the experiments were conducted. Even though the variations in room air temperature were not large $( \pm 0.9 \mathrm{~K})$, the inconsistent ambient temperature led to inconsistent manikin surface temperature. Thus, the difference between the air temperature and the surface temperature was not constant through the experimental cases; ergo, the air velocity in the convective boundary layer was not constant as well [18]. Such variations restrict the possibility of a direct comparison of the interaction between the free convective flow and the personalized flow during multiple cases. Further technical limitations during the schlieren visualizations included heating the supplied PV air to achieve a different density from the surrounding room air. However, PV is typically used in the cooling mode. This caused the supplied air to bend upwards instead of downwards.

\section{Acknowledgement}

This work was supported by a scholarship from the Deutscher Akademischer Austauschdienst (DAAD) under the Research Grants - Doctoral Programmes in Germany (programme ID: 57129429). Their constant support is highly cherished and appreciated. The authors would also like to express their gratitude to Mr. Robin Hansmeier for his assistance in conducting the schlieren visualization.

\section{References}

[1] Melikov A. Personalized ventilation. Indoor Air 2004;14(s7):157-67. doi:10.1111/j.1600-0668.2004.00284.x. [2] Chludzińska M, Bogdan A. The effect of temperature and direction of airflow from the personalised ventilation on occupants' thermal sensations in office areas. Building and Environment 2015;85:277-86.

[3] Melikov A, Cermak R, Majer M. Personalized ventilation: Evaluation of different air terminal devices. Energy and Buildings 2002;34(8):829-36.

[4] Kaczmarczyk J, Melikov A, Bolashikov Z, Nikolaev L, Fanger PO. Human response to five designs of personalized ventilation. HVAC\&R Research 2006;12(2):367-84.

[5] Yang B, Melikov A, Sekhar C. Cooling effect of ceiling mounted personalized ventilation system. Proceedings of Indoor Air, Copenhagen, Denmark. Paper ID: 852;2008.

[6] Yang B, Melikov A, Sekhar C. Performance evaluation of ceiling mounted personalized ventilation system. ASHRAE Transactions 2009;115:395-406.

[7] Bolashikov Z, Melikov A, Spilak M. Experimental investigation on reduced exposure to pollutants indoors by applying wearable personalized ventilation. HVAC\&R Research 2013;19(4):385-99.

[8] Bolashikov Z, Melikov A, Krenek M. Control of the free convective flow around the human body for enhanced inhaled air quality: Application to a seat-incorporated personalized ventilation unit. HVAC\&R Research 2010;16(2):161-88.

[9] Halvoňová B, Melikov A. Performance of "ductless" personalized ventilation in conjunction with displacement ventilation: Impact of intake height. Building and Environment 2010;45(4):996-1005.

[10] Alsaad H, Voelker C. Performance assessment of a ductless personalized ventilation system using a validated CFD model. Journal of Building Performance Simulation 2018;11(6):689-704.

[11] Schiavon S, Melikov A, Sekhar C. Energy analysis of the personalized ventilation system in hot and humid climates. Energy and Buildings 2010;42(5):699-707.

[12] Sekhar C, Zheng L. Study of an integrated personalized ventilation and local fan-induced active chilled beam air conditioning system in hot and humid climate. Building Simulation 2018;11(4):787-801.

[13] Melikov A. Human body micro-environment: The benefits of controlling airflow interaction. Building and Environment 2015;91:70-7.

[14] Lewis HE, Foster AR, Mullan BJ, Cox RN, Clark RP. Aerodynamics of the human microenvironment. The Lancet 1969;293(7609):1273-7.

[15] Clark RP, Toy N. Forced convection around the human head. The Journal of Physiology 1975;244(2):295-302.

[16] Holmberg RB, Eliasson L, Folkesson K, Strindehag 0. Inhalation Zone air quality provided by displacement ventilation. Proceedings of Roomvent '90, Oslo, Norway 1990. [17] Rim D, Novoselac A. Transport of particulate and gaseous pollutants in the vicinity of a human body. Building and Environment 2009;44(9):1840-9.

[18] Voelker C, Maempel S, Kornadt O. Measuring the human body's microclimate using a thermal manikin. Indoor Air 2014;24(6):567-79.

[19] Licina D, Melikov A, Sekhar C, Tham KW. Air temperature investigation in microenvironment around a human body. Building and Environment 2015;92:39-47.

[20] Licina D, Pantelic J, Tham KW, Sekhar C. Experimental characterization of the human convective boundary layer in a calm indoor environment. Proceedings of ASHRAE IAQ 2013: Environmental Health in Low Energy Buildings, Vancouver, Canada 2013.

[21] Licina D, Pantelic J, Melikov A, Sekhar C, Tham KW. Experimental investigation of the human convective boundary layer in a quiescent indoor environment. Building and Environment 2014;75:79-91.

[22] Zukowska D, Melikov A, Popiolek Z. Impact of personal factors and furniture arrangement on the thermal plume above a sitting occupant. Building and Environment 2012;49:104-16.

[23] Homma H, Yakiyama M. Examination of free convection around occupant's body caused by its metabolic heat. ASHRAE Transactions 1987;93:104-24.

[24] Licina D, Melikov A, Sekhar C, Tham KW. Human convective boundary layer and its interaction with room ventilation flow. Indoor Air 2015;25(1):21-35. 
[25] Craven BA, Settles GS. A computational and experimental investigation of the human thermal plume. Journal of Fluids Engineering 2006;128(6):1251-8.

[26] Voelker C, Alsaad H. Simulating the human body's microclimate using automatic coupling of CFD and an advanced thermoregulation model. Indoor Air 2018;28(3):415-25.

[27] Bolashikov ZD, Melikov A, Kranek M. Improved performance of personalized ventilation by control of the convection flow around an occupant's body. ASHRAE Transactions 2009;115, Part 2:421-31.

[28] Settles GS. Schlieren and shadowgraph techniques: Visualizing phenomena in transparent media. Berlin, Germany: Springer-Verlag GmbH; 2001.

[29] Harvey JS, Smithson HE, Siviour CR. Visualization of acoustic waves in air and subsequent audio recovery with a high-speed schlieren imaging system: Experimental and computational development of a schlieren microphone. Optics and Lasers in Engineering 2018;107:182-93.

[30] Ting C-C, Chen C-C. Detection of gas leakage using microcolor schlieren technique. Measurement 2013;46(8):2467-72.

[31] Rothenfluh T, Schuler MJ, Rohr PR von. Penetration length studies of supercritical water jets submerged in a subcritical water environment using a novel optical Schlieren method. The Journal of Supercritical Fluids 2011;57(2):17582.

[32] Tang JW, Nicolle ADG, Pantelic J, Jiang M, Sekhr C, Cheong DKW et al. Qualitative real-time schlieren and shadowgraph imaging of human exhaled airflows: an aid to aerosol infection control. PLoS ONE 2011;6(6):e21392.

[33] Xu C, Nielsen PV, Liu L, Jensen RL, Gong G. Human exhalation characterization with the aid of schlieren imaging technique. Building and Environment 2017;112:190-9.

[34] Tang JW, Nicolle A, Pantelic J, Koh GC, Wang LD, Amin $\mathrm{M}$ et al. Airflow dynamics of coughing in healthy human volunteers by shadowgraph imaging: an aid to aerosol infection control. PLoS ONE 2012;7(4):e34818.

[35] Tang JW, Liebner TJ, Craven BA, Settles GS. A schlieren optical study of the human cough with and without wearing masks for aerosol infection control. Journal of the Royal Society Interface 2009;6 Suppl 6:S727-36.

[36] Tang JW, Nicolle AD, Klettner CA, Pantelic J, Wang L, Suhaimi AB et al. Airflow dynamics of human jets: sneezing and breathing - potential sources of infectious aerosols. PLoS ONE 2013;8(4):e59970.

[37] Arghand T, Karimipanah T, Awbi HB, Cehlin M, Larsson U, Linden E. An experimental investigation of the flow and comfort parameters for under-floor, confluent jets and mixing ventilation systems in an open-plan office. Building and Environment 2015;92:48-60.

[38] Sales RBC, Pereira RR, Aguilar MTP, Cardoso AV. Thermal comfort of seats as visualized by infrared thermography. Applied ergonomics 2017;62:142-9.

[39] Cehlin M, Moshfegh B, Sandberg M. Visualization and measuring of air temperatures using infrared thermography.
Proceedings of Roomvent 2000, the 7th International Conference on Air Distribution in Rooms, Reading, UK 2000;1:339-47.

[40] Cehlin M, Moshfegh B, Sandberg M. Measurements of air temperatures close to a low-velocity diffuser in displacement ventilation using an infrared camera. Energy and Buildings 2002;34(7):687-98.

[41] Gena AW, Voelker C. New schlieren imaging system: setup and first results. Proceedings of Roomvent \& Ventilation 2018, Espoo, Finland 2018:391-6.

[42] ISO 7726. Ergonomics of the thermal environment Instruments for measuring physical quantities. Switzerland: International Organization for Standardization; 2002.

[43] Farnebäck G. Two-frame motion estimation based on polynomial expansion. Proceedings of the 13th Scandinavian Conference on Image Analysis SCIA, Halmstad, Sweden 2003:363-70.

[44] Voelker C, Kornadt O. Automated coupling of CFD and human thermoregulation modelling considering local climatic parameters. Proceedings of the 5th International Building Physics Conference IBPC, Kyoto, Japan 2012:945-51.

[45] Fanger 0. What is IAQ? Indoor Air 2006;16(5):32834.

[46] Zhang H, Arens E, Huizenga C, Han T. Thermal sensation and comfort models for non-uniform and transient environments: Part I: Local sensation of individual body parts. Building and Environment 2010;45(2):380-8.

[47] Zhang H. Human thermal sensation and comfort in transient and non-uniformthermal environment [Ph.D. thesis]: Center for the Built Environment, University of California, Berkeley; 2003.

[48] Zhang H, Arens E, Huizenga C, Han T. Thermal sensation and comfort models for non-uniform and transient environments, part II: Local comfort of individual body parts. Building and Environment 2010;45(2):389-98.

[49] Zhang H, Arens E, Zhai Y. A review of the corrective power of personal comfort systems in non-neutral ambient environments. Building and Environment 2015;91:15-41.

[50] Cabanac M. Pleasure: The common currency. Journal of Theoretical Biology 1992;155(2):173-200.

[51] Cabanac M. Physiological Role of Pleasure. Science 1971;173(4002):1103-7.

[52] Attia M. Thermal pleasantness and temperature regulation in man. Neuroscience \& Biobehavioral Reviews 1984;8(3):335-42.

[53] Parkinson T, de Dear R. Thermal pleasure in built environments: Spatial alliesthesia from air movement. Building Research \& Information 2016;45(3):320-35. 